\title{
The Distance between Opera and Ordinary People - Discussion on the Development of the Chinese Opera Market
}

\author{
Hongxing Ren \\ School of Music, Shaanxi Normal University, Xi'an, 710119, China
}

\begin{abstract}
Keywords: opera, Chinese opera, musical aesthetics, development, innovation, communication, market positioning
\end{abstract}

\begin{abstract}
Opera was sourced from Europe. In the late Ming and early Qing dynasties, western Catholics spread opera into China in the name of missionary activity. Till the 1920s, opera really sprouted in China. Up to now, it has been approximately a hundred years for the development of opera in China. In practice, however, opera is not stable in China. It used to have the "Chinese opera crisis". In this paper, the author explained the current situation and the development tendency of the Chinese opera market from multiple perspectives, and proposed some constructive suggestions.

The origin Chinese opera used for reference the scale of western opera. It is a kind of traditional inheritance of art. The development of Chinese opera is influenced by traditional musical aesthetics through and national characters of Chinese culture. Therefore, Chinese opera has its unique charms. In fact, however, Chinese people experienced a long process of gradual understanding and adaption from passiveness and curiosity to conscious learning due to Chinese nation's deep-rooted aesthetic consciousness and mood of national culture.
\end{abstract}

\section{Opera}

The word of opera was sourced from its hometown - Italy. At the early 17th century, opera was born in Florence. Its origin was the theatre music in ancient Greek drama. Compared with ancient artistic form of drama, opera is the same as drama in terms of performance. Both items need typical theatre elements, such as the background, props, costumes and the performance of performers. However, opera is also different from drama. The former lays particular emphasis on vocal music techniques and music attainments of performers. Some operas even require the performers to have a certain foundation of dance performance. For instance, the performance of ballet was integrated into some French dramas in the later stage. Therefore, opera is deemed as an important part of classical music traditions in western countries. European people love classical music very much, so opera is also loved by European people. Its popularity even surpasses classical music and pop music. Opera is in a rather high position in the heart of European people.

\section{Chinese Opera}

\section{(I) Development}

Chinese opera was born in the 1920s. After the May 4th Movement, Chinese composers used for reference and absorbed creative ideas and artistic forms of western musical culture based on the aesthetic ideology of Chinese traditional music, integrated the type of western opera with the pattern of Chinese traditional drama, and created early opera works (such as Qiuzi, Little Painter, Land Clearing by Brother \& Sister and White Haired Girl) in succession, expanding a piece of the world for the early development of Chinese opera.

(II) Current situation

With the growth in the living standards of Chinese people, economic benefits under the market economic system receive more and more attention from people. Driven by benefits, some creators in the Chinese opera market are led to loose the principle for opera creation. They even abandoned Chinese traditional temperament, overlooked the public aesthetic taste, and sought quick success and instant benefits. As a result, this makes the Chinese opera market to suffer from a kind of strike 
different from the Cultural Revolution. If the impact from the Cultural Revolution is short and external, then the blow on opera in the new period is internal and in the consciousness, maybe difficult to be changed even in a long period. It is impossible for opera to enter the innermost of Chinese audiences or form a kind of national culture and aesthetic value. For Chinese opera involved in continuous innovation to the list of plays and a probable failure in costs, this undoubtedly is an unprecedented test of survival.

\section{Issues Existing in the Current Development of Chinese Opera}

According to the author, the following development shackles exist for Chinese opera at present when viewed from artistic creation and market management. These shackles restrained the development of Chinese opera, and also objectively caused the failure of Chinese opera to enter the innermost of people.

(I) Creative ideas

Opera is a kind of comprehensive form of art integrated with music singing, dance and dramatic performance. Opera lays emphasis on plot development as well as artistic expression, and strives to describe and highlight dramatic conflicts by concentrating means of artistic expression. Thus, it is necessary for creators to have extremely strong creative ideas, inject a soul to opera, and improve the taste and the artistic height of opera. Although some Chinese opera works won the praise from the times and the society, they still lacked relations with the practice as well as the deepening into the actual life of common people. It can be put in this way the art of Chinese opera is too "higher than life". This is a non-rational creation idea. This idea is also unpractical, which cannot keep up with the times and make the audiences to resonate.

(II) Music conflict

Opera is served as the musical form of drama. Its musical expression is stronger than musical drama and movie. Opera sublimates the framework of the whole drama plot. Musical logics, story clues, drama figures and changes in stage scenes and lamplight displayed in the drama plot will change with the changes in music rhythm and emotions, so as to create dramatic conflicts. Drama cannot be separated from conflict. So does it for opera. Moreover, stage opera has more limits than drama. The reason is that stage opera needs to display various complicated contradictions of thinking, characters and emotions through musical forms. However, stage opera cannot directly express thoughts and emotions as free as music. Therefore, stage opera creates personal characters, and extracts plot conflicts in various limits. It is the most difficult part for opera to reflect infiniteness with finiteness. In terms of such expression, Chinese opera is not strong or even weak somewhat. Chinese opera lacks inspiring dramatic conflicts. Moreover, it is even difficult to find the role of music in adding fuel to the fire for the plot of opera. Sometimes, music is better than the opera, covering up the expressive force of opera. Sometimes, the function of music is overlooked while organizing dramatic conflicts. As a result, the integrity of opera is greatly influenced, letting the audiences fail to see the existence of musical image in opera. This remarkably reduces the infection of each artistic expression in opera. Comprehensively, it fails to reach the expected height with respect to theatricality, lyricism and conflict of opera. The occurrence of the said circumstances in Chinese opera is correlated with the shortage of excellent drama and music creators in China. Moreover, it even lacks the perfect combination of two kinds of creators. Generally speaking, it is really sparse for classical and impressive music arias in Chinese opera.

(III) Lyric arias

Plots and objects expressed in opera are meant to leave an imaginary space for the audiences instead of arias without a pause. In Chinese opera, Lyric arias are too long, which influences the rhythm of the audiences' emotions into the plot of opera, and destroys the massive structure of opera. Although opera is mainly of music, the originally beautiful arias will also become disgusting, let alone leaving an expression to the audiences, if lyric arias appear at improper positions or are repeated. Therefore, for the development of Chinese opera, it is also rather necessary for the design and change in the opera structure.

(IV) Creators 
Rejuvenation of creators is also a major reason for the failure of Chinese opera to have qualitative improvement. At present, the creation team of opera is young in China. They are the future of Chinese opera, but their extraction and understanding is not deep for Chinese traditional art, folk music and folk song culture in opera. Moreover, many creators are influenced by the culture of contemporary western opera to a large extent. Some people learnt about the art of western opera for many years in overseas countries. Therefore, it is unexpected no matter for the creation techniques of music or the cognition of Chinese traditional culture. This Westernized development tendency of opera allows the development space of Chinese traditional opera to become smaller and smaller. Moreover, there are also fewer opera works in the Chinese style which can cause strong resonance for Chinese people. The reason is that Chinese opera music creators failed to deepen into the practical life and understand the Chinese culture and society.

(V) Excellent plays

Play is served as the basis for opera. In the great prosperity period of opera in the 1950s - 1960s in China, excellent works emerged in endlessly, such as White Haired Girl, The Red Guards on Honghu Lake and Sister Jiang. These works reflect the era characteristics of China and the unique charm of Chinese opera. After the 1980s, however, the inspiring excellent plays became rare and precious in Chinese opera. In the circle of Chinese opera, the shortage of opera plays with high quality and creative ideas is a great bottleneck for the development of Chinese opera. Many opera works at present failed to reflect social value and artistic value. The contents are vacuous. This reflects the awkward development situation of Chinese opera at present from one side.

(VI) The public aesthetics

On the one hand, whether opera creates artistic value is decided by the public's aesthetic orientation. Although different audiences have different aesthetic tastes, different levels of appreciation, and different choices and judgments of works, the artistic expression of an excellent opera which can cause the public's resonance is the same as the cultural connotation to be expressed. Chinese opera lacks the inheritance of Chinese traditions. Moreover, it fails to grasp the pulse of the times and deepen into the public's life. Chinese opera works by no means conform to aesthetic demands of modern audiences. For example, only those works can attract the public's eyes, such as the story close to the public's life as Camp Field and the classical work as Thunderstorm which can express love and hatred of a family with a classical novel as the plot support. Additionally, Chinese audiences were also impacted by western culture in the last 30 years. It gives expression to the fact that Chinese people in modern times love western culture very much and that some pop cultures easier to be accepted by young and middle-aged people was full of the market. Therefore, the public in China generally deemed opera as "high culture". When opera is performed in urban theaters, the present scene is "on the shelf" and then the silent "disappearance from the scene". In my opinion, it is impossible for opera to be accepted by Chinese audiences. Its basic reason is that it is impossible for opera to form a kind of mass culture in China. The fundamental reason lies on the shortage of opera and even the whole music education in China.

(VII) Marketing

Values and survival modes of Chinese audiences also influenced the development pattern of opera in China. That is a development pattern of "being lonely at the top". With the rapid development of modern society, the cultural pattern appreciated by people also trends to be simple and quick. Modern people pursue for a simple and refreshing mode of recreation as well as simple excitement beyond the work and life pressure. The extremely emotional artistic form with slow rhythm as opera cannot grasp the inward world of modern audiences. Nowadays, people seldom select opera which is not economic due to expensive production costs in terms of the selection of diversified forms of art. If it continues this way, people's aesthetic habits will change with the change in appreciation mode. Moreover, the producers also failed to advertise opera in place. Therefore, it is easy for the Chinese opera marketing to appear the phenomenon of self-financing. Compared with the practice of positively self marketing and cultivating audiences from the basic level in Europe, America, Japan and other countries in terms of business operations of opera, China still has many immature places in the marketing promotion of opera. For instance, the producers 
lack the research on changes in the audiences' aesthetics, show no or inadequate respect to appreciation habits of national culture, and have a long distance from the public.

\section{Countermeasures for the Development of Chinese Opera}

From the children's opera of Li Jinhui to the present, the development of Chinese opera experienced the process of exploration, development, maturity, crisis and re-exploration. A group of excellent opera works with Chinese characteristics also withstood the test of time. So far, some works can also cause wide resonance. However, changes in complicated social environment and people's aesthetic values let it difficult for the development of opera in China. Since the 1990s, Chinese opera stage had a sign for recovery. Some excellent works emerged one after another, including Chinese Orphan, Thunderstorm and Camp Field. These works injected fresh blood to the development of Chinese opera undertakings. However, this is far from enough the ideal goal of Chinese opera undertakings. For a better future for Chinese opera undertakings, the author thinks that we should achieve the following aspects:

(I) Enhance music education

The development of music should have positive social orientation as well as the pursuit for the improvement to national music quality. For the development of the Chinese opera market, we should lay emphasis on the work of music education with social benefits, especially for teenagers. In western countries, all children will receive the education of classical music and even ballet classes from childhood. Moreover, emphasis is laid on the cultivation of the students' basic education of music and the improvement to shape and temperament from childhood, namely the cultivation of aesthetic education. In this aspect, Chinese education is extremely insufficient. Therefore, China should start from children in terms of aesthetic education (such as music), and cultivate the students' cognition of music from childhood, especially for the education of national music culture. As the foundation of Chinese opera, national music culture is of great importance for Chinese people to acknowledge and appreciate the artistic form of opera in the future.

(II) Encourage innovations

The Ministry of Culture of China has four conditions for the review for Chinese stage arts. The first one is that stage artistic works should be provided with time spirit. The second one is to have innovative value and contribute to promote the inheritance and development of this artistic form. The third one is to have unique artistic expression and infection, letting artistic works to have relatively high vitality and artistic values. The fourth one is to allow the masses to love to see and hear and suit both refined and popular tastes. While carrying forward national art culture, we should also attach importance to the conformity with the public's aesthetic demands.

(III) Close to the audiences

Chinese opera should completely eradicate the artistic atmosphere of "being lonely at the top", and create opera works which Chinese audiences love to see and hear. Such opera works can conform to national conditions and the principles of social development. Music is served as the foundation of human culture and art, so it is ivory-towered for elegant individuality separated from wide audiences' cultural needs and pursuits. Chinese opera should be created from the angle of the audiences by adhering to the combination of excellent national culture music with contemporary people's social consciousness. Moreover, Chinese opera should also deepen into the public's life to extract the essence, and communicate with the audiences in the form of opera, so as to get closer to the audiences.

\section{Summary}

The development of Chinese opera has already experienced a history of approximately a hundred years. Many people contributed a lot to Chinese opera. Moreover, Chinese opera also obtained remarkable achievements. The most importantly, we should enhance the understanding of all sectors of society toward the art culture of opera, pay attention to the importance of music education for the future development of China, form a kind of virtuous circle for the development and 
inheritance of opera in China, and achieve healthy growth of Chinese opera undertakings.

\section{References}

[1] Man Xinying, Birth of Chinese Opera [D], Xiamen University, 2006;

[2] Li Jichao, Discussion on Development and Modem Communication of Chinese Opera Art [J], Theory Research, 2012 (29);

[3] Jia Yonghong, My Opinions on Innovative Development of Chinese Modern Opera [J], Music Space, 2013 (9) 